\title{
The Practical Potential of Bacilli and Their Enzymes for Industrial Production
}

\author{
Iuliia Danilova* and Margarita Sharipova
}

Department of Microbiology, Institute of Fundamental Medicine and Biology, Kazan Federal University, Kazan, Russia

Bacillus spp. are an affordable source of enzymes due to their wide distribution, safety in work, ease of cultivation, and susceptibility to genetic transformations. Researchers are particularly interested in proteolytic enzymes, which constitute one of the most diverse groups of microbial proteins in terms of properties. Despite the long history of their research, this group of enzymes continue to show great potential for practical application in the biomedical industry, as well as in the agricultural industry. Thus, the unique properties of bacillary proteinases, such as stability in a wide range of temperatures and $\mathrm{pH}$, high specificity, biodegradability of a wide range of substrates, and the high potential of sequenced Bacillus genomes are a powerful foundation for the development of new biotechnologies. The current review aims to discuss recent studies on various enzymes

OPEN ACCESS

Edited by:

Carlos Alberto Moreira-Filho, University of São Paulo, Brazil

Reviewed by: Oleg Reva,

University of Pretoria, South Africa Michael Leonidas Chikindas,

Rutgers, The State University of New Jersey, United States

*Correspondence: Iuliia Danilova iuliiav.danilova@gmail.com; danilova146@mail.ru

Specialty section: This article was submitted to Microbiotechnology, a section of the journal Frontiers in Microbiology

Received: 03 May 2020

Accepted: 07 July 2020

Published: 04 August 2020

Citation:

Danilova I and Sharipova M (2020) The Practical Potential of Bacilli and

Their Enzymes for Industrial Production.

Front. Microbiol. 11:1782. doi: 10.3389/fmicb.2020.01782 in particular, proteinases produced by bacteria of the genus Bacillus, along with their prospective practical applications. This article also presents an interpretive summary of the recent developments on the usage of probiotic Bacillus strains as potential feed additives.

Keywords: microbial enzymes, proteases, Bacillus, applications, medicine, agriculture, microbiology

\section{INTRODUCTION}

Enzyme-based technologies guarantee efficient utilization of raw materials and generation of minimal or no wastes and shun the usage of toxic chemicals (Singh and Bajaj, 2016, 2017). The industrial application of enzymes may contribute significantly toward the development of environmentally benign processes (Mhamdi et al., 2017). The main advantages of enzymatic methods include: reduced energy requirements, increased product yield, increased catalytic efficiency, and reduced catalyst losses and by-products. Peptide hydrolases or proteases refer to a large group of proteolytic enzymes that hydrolyze peptide bonds in proteins and peptides (Gurumallesh et al., 2019). The scope of proteinase research is steadily increasing due to the abundance of information on the microbial genome that paves way for new techniques based on genetic engineering, genomics and proteomics. Bacteria are the most dominant group of protease producers with the genus Bacillus being the most prominent source (Mienda et al., 2014). This is mainly due to the high capacity for protein secretion that several Bacillus species possess (Harwood and Cranenburgh, 2008; Cui et al., 2018). In addition, different species of the Bacillus genus produce neutral and alkaline proteases (Anandharaj et al., 2016; Rehman et al., 2017), which is interesting for enzyme use in industry. Another approach is genetic engineering of proteases from Bacillus sp., strains, resulting in proteases with differentiated properties. Additionally, Bacillus species have been studied for the heterologous production of proteases from other microorganisms, including different Bacillus species (Cui et al., 2018). 
Bacillus proteases have several remarkable characteristics for many industrial applications such as broad $\mathrm{pH}$ and temperature activity, stability range, alkaline and toxic compounds tolerance, including oxidants and surfactants (Contesini et al., 2018). Based on these interesting aspects, proteases from the genus Bacillus are used in the production of detergents, food products, leather, silk, and agrochemical products (Dos Santos Aguilar and Sato, 2018; Razzaq et al., 2019). The alkaline serine protease (DHAP) from Bacillus pumilus BA06 is a typical mesophilic enzyme, which has demonstrated great potential in various industrial applications (Zhao and Feng, 2018). The multiple applications presently using alkaline proteases are reported in the article of Kamal et al. (2016). It focuses on the updated tidings on nutritional effects, physiochemical parameters, biochemical aspects, and strain improvement methodologies for hyperproduction of protease (Kamal et al., 2016). In the review of Gurumallesh et al. (2019), the potential utilizations of the enzyme in a variety of industries is described.

Probiotics use in agriculture has gained attention as microbial candidates to maintain the health and the wellbeing of many animals. Among the many microbial candidates, probiotic Bacillus has sporulation capacity that makes them survive harsh environmental conditions, is non-pathogenic and non-toxic when fed to animal, and can produce antimicrobial substances making them more suitable candidates compared to other probiotics (Kuebutornye et al., 2019).

Bacilli and their proteases have received renewed attention due to increasing demands in medical and industrial commodities. Not so much data on Bacillus proteinase-based drugs with prospective applications in agriculture and medicine can be found in the literature. For instance, Razzaq et al. (2019) confirmed the potential use of proteinase-based preparations in industry, for the production of textiles, leather, food, and detergents.

This manuscript summarizes data on Bacillus enzymes, which have potential applications in agriculture and pharmaceutical industries, especially in thrombolytic therapy and the treatment of neurodegenerative diseases.

\section{THE USE OF MICROBIAL ENZYMES IN MEDICINE}

The lack of therapeutic agents in areas such as cardiovascular medicine and the treatment of neurodegenerative diseases remains the basis in the search for novel therapeutic (enzymatic) drugs. Microbial enzymes are used in the production of beta-lactam antibiotics, such as semisynthetic penicillins and cephalosporins (Volpato et al., 2010). Some drugs used to lower blood cholesterol are likewise based on microbial enzymes (Ma et al., 2010).

Microbial enzymes can be directly used as medications. In therapy, lysing agents, such as streptokinases (Streptococcus haemolyticus) and staphylokinases (some strains of Staphylococcus aureus; Jespers et al., 1999), are widely used as fibrinolytics in treating thrombosis. Terrilitins (Aspergillus tericola) are known to aid in the treatment of wounds, trophic wounds, and burns (Shataeva et al., 1973; Khmelevskaia, 2000). Additionally, lipases (Bacillus, Acinetobacter, Propionibacterium, Chromobacterium, and Alkaligenes) hydrolyze fats in chronic gastrointestinal diseases (Hasan et al., 2006). Alkaline proteases from Bacillus subtilis act as efficient transdermal drug delivery system for dermatological applications (Nounou et al., 2017). Furthermore, amylases (Bacillus) hydrolyzes starch used for pancreatic insufficiency, etc., (Souza and Magalhaes, 2010; Jujjavarapu and Dhagat, 2019).

At present, most biological products are obtained based on genetically modified organisms. The main producers of recombinant enzymes are bacteria, such as Escherichia coli, B. subtilis, Lactobacillus lactis, and yeast, including Pichia pastoris (Baneyx, 1999; Yang et al., 2011; Garcia-Fruitos, 2012; Suleimanova et al., 2016; Cui et al., 2018; Troshagina et al., 2018). Cardiovascular and oncological diseases, as well as Alzheimer's disease (AD), are among the most common causes of death. The treatment of these formidable diseases continues to be one of the most pressing issues in modern medicine. This necessitates the search for new potential microbial proteins for prospective use in medicine and pharmacy.

\section{Fibrinolytic Enzymes of the Genus Bacillus}

Fibrinolytic proteases are a promising alternative to existing drugs for thrombolytic therapy. Fibrinolytic enzymes are obtained from diverse microorganisms, the most important of which are representatives of the genus Bacillus. Less than two decades ago, the enzyme preparation thrombovazim was developed by Plotnikov et al. (2009) in Russia that based on the subtilase of B. subtilis, which has since then been adopted for the treatment of acute myocardial infarction and unstable angina (Plotnikov et al., 2009). Thrombovazim is a $B$. subtilis proteinase preparation immobilized on polyethylene oxide and has no analoges among the drugs with similar mechanism of action. Thrombovazim has low toxicity, which grants the possibility of its use in both hospital and extramural settings (Plotnikov et al., 2009).

However, the lack of efficient thrombolytics is a primary factor, which drives the intensive hunt for new enzymes from microorganisms with high thrombolytic activity. Subtilisin DFE, a serine proteinase with fibrinolytic properties, is expressed in the protease-deficient strain of B. subtilis WB600 (Peng et al., 2004). Proteinases QK-1 and QK-2 obtained from B. subtilis QK02 and a subtilisin-like proteinase acquired from B. subtilis TP-6 have a high level of fibrinolytic activity and are promising for thrombolytic therapy (Ko et al., 2004; Kim et al., 2006). For instance, in the subtilisin-like proteinase FS33 isolated from B. subtilis DC33, the level of fibrinolytic activity was six times higher than the activity level of Carlsberg subtilisin. This enzyme destroyed fibrin clots by forming active plasmin from plasminogen, as well as by direct lysis of fibrin clots (Wang et al., 2006). Several serine fibrinolytic proteinases have been described such as: proteinases secreted by B. subtilis LD-8547 (Wang et al., 2008); subtilisin BSF1 from B. subtilis A26 and BAF1 produced by Bacillus amyloliquefaciens An6 (Agrebi et al., 2009, 2010); recombinant subtilisin of $B$. subtilis PTCC 1023 expressed in E. coli BL21 (DE3; Ghasemi et al., 2012); and subtilisin-like serine proteinase isolated from the marine strain B. subtilis ICTF-1 (Mahajan et al., 2012); as well as the enzyme secreted by Bacillus cereus SRM-001 (Narasimhan et al., 2018). Serine proteinases of B. pumilus 7P have fibrinolytic activity but are unable to 
activate plasminogen. Beyond that, the thrombolytic activity of these enzymes has been shown to be dose-dependent (Danilova et al., 2012). Currently, the B. subtilis C10 strain is considered prospective for cost-effective production of fibrinolytic serine protease (Thu et al., 2019). The strain Bacillus velezensis BS2, which was isolated from marine squirt (munggae) jeotgal, produces an enzyme that exhibits strong fibrinolytic activity (Yao et al., 2019).

In the event of an abridged function of the body's anticoagulant system, the lysis of one blood clot does not rule out the formation of new blood clots. Hence, the administration of anticoagulants coupled with thrombolytic drugs to impede the development and growth of blood clots is cardinal for patients.

In line with this, Indian scientists discovered bafibrinase, a serine proteinase of Bacillus sp., AS-S20-I with a molecular weight of $32.3 \mathrm{kDa}$, which exhibits thrombolytic and anticoagulant properties (Mukherjee et al., 2012). Thrombolytic activity along with plasminogen activation was shown by two proteolytic enzymes with molecular weights 29 and $29.5 \mathrm{kDa}$ produced by Bacillus halodurans IND18 and B. cereus IND1, respectively (Vijayaraghavan and Vincent, 2014). The $20.5 \mathrm{kDa}$ metalloprotease was purified from B. subtilis $\mathrm{K} 42$, which also showed fibrinolytic and anticoagulant potential (Hassanein et al., 2011). Subtilisin-like proteinase and glutamyl endopeptidase of B. pumilus 7P possess noticeable anticoagulant properties (Danilova et al., 2012).

With the development of post-genomic technologies, there has been a tendency to replace drugs of animal origin with affordable microbial drugs. In this regard, the intensive search for strains producing proteases with high fibrinolytic, thrombolytic, and anticoagulant activity is relevant. Thus, Bacillus proteinases are potential enzymes for use in the development of thrombolytic drugs.

\section{Microbial Enzymes Targeting Amyloid Plaques and Prion Complexes}

Alzheimer's disease (dementia) is one of the common pathologies of the central nervous system. Amyloid plaques containing amyloid beta protein, which also accumulates in the walls of the cerebral arteries, are found in the interstitial fluid of the brain. Amyloid plaques are deposits of beta-amyloid $(A \beta)$ peptides, with a size of 42 amino acid residues (Hardy and Selkoe, 2002). A $\beta$ is formed due to the enzymatic cleavage of its precursor (amyloid precursor protein, APP), usually present in the membranes of neurons and other cells.

A strain of the genus Bacillus, which produces a protease exhibiting high degradation activity against PrPSc, has been characterized. Sequence analysis showed that the serine protease of this strain belongs to the subtilisin family and has optimal $\mathrm{pH}$ and temperature ranges of $9-10$ and $60-70^{\circ} \mathrm{C}$, respectively. Western blot analysis showed that the protease is also able to decompose homogenate of brain affected with bovine spongiform encephalopathy. In addition, it was shown that protease much more effectively destroys dried PrPSc, firmly attached to a plastic surface, in comparison with proteinase $\mathrm{K}$ or the previously reported keratinase of Bacillus licheniformis PWD-1 (Yoshioka et al., 2007). Another study described a hyperthermostable protease, Tk-subtilisin, which successfully breaks down PrPSc under extreme conditions (Koga et al., 2014).
These data may be useful in studying the activity of bacillary proteinases, especially with respect to $A \beta$, which causes $A D$. For example, a $\mathrm{A} \beta$ peptide ( 42 amino acid residues) was cleaved by $B$. pumilus 7P proteinases (glutamyl endopeptidase, subtilisinlike proteinase, and metalloproteinase), resulting in the formation of a non-pathogenic form of the peptide that lacks the ability to form plaques. All studied proteinases hydrolyzed amyloid beta, but the most promising in practical application are glutamyl endopeptidase and metalloproteinase, which can inactivate the Glu11-His14 beta amyloid dimerization initiation site (Danilova et al., 2014).

The nattokinase of B. subtilis natto described earlier, proteinase $\mathrm{K}$ and Carlsberg subtilisin, have the ability to hydrolyze amyloid (Hsu et al., 2009). These proteins have also been offered as potential agents for the development of drugs against $\mathrm{AD}$.

A multipurpose approach using biological preparations aimed at prion proteins opens up great prospects for the development of effective therapeutic interventions for $\mathrm{AD}$.

\section{Bacillus Enzymes for Biofilm Destruction}

It is now recognized that most microbes live in complex communities called biofilms. In a biofilm, individual cells are consolidated by an extracellular polymer matrix, usually consisting of polysaccharides, proteins, and DNA (Flemming et al., 2016). The biofilm lifestyle offers several benefits for microbes. For example, microorganisms within a biofilm can gain access to inaccessible nutrients and protect themselves against environmental fluctuations (Costerton et al., 1995). However, the negative repercussions in the formation of biofilms lies in the immense problem they present in health care, agriculture, and industry.

One of the methods to combat biofilms is the use of proteases. The anti-biofilm activity of bacillary proteases has already been tested on a large number of bacterial biofilms: Pseudomonas, Acinetobacter, and Serratia (Elchinger et al., 2015; Galie et al., 2018). For instance, a neutrase from B. amyloliquefaciens is known to exhibit endoprotease activity under neutral conditions (Elchinger et al., 2014). The protease from B. licheniformis (cited as Protease B) is a serine-type endoprotease that hydrolyzes most peptide bonds between $\mathrm{pH} 6.5$ and 8.5, with an optimal temperature of $60^{\circ} \mathrm{C}$, and is also used in biofilm regulation (Thallinger et al., 2013). The alkalase from B. licheniformis is a serine endopeptidase, mainly consisting of subtilisin $A$, which has been used in the paper industry to remove biofilms of various bacterial species (Marcato-Romain et al., 2012).

The effect of the proteolytic enzymes B. pumilus 3-19 on the structure of Serratia marcescens biofilms was studied. High efficacy of treatment with subtilisin-like protease and glutamyl endopeptidase for biofilm removal has been demonstrated. Enzymatic processing led to the degradation of EPS components and significant destruction of biofilms (Mitrofanova et al., 2017).

Bacillus spp. synthesize a large number of enzymes, amino acids, and other biologically active substances that destroy biofilms (Elchinger et al., 2015). The antibacterial activity of the antimicrobial peptide (CSpK14) isolated from B. amyloliquefaciens in combination with $\beta$-lactams against vancomycin-resistant strains of S. aureus (VRSA) and Enterococci (VRE) has been 
well established (Regmi et al., 2017). Chitosanase synthesized by $B$. licheniformis inhibited the biofilm formation of Pseudomonas aeruginosa and Klebsiella pneumoniae to about 22 and 29\%, respectively, relative to a $100 \%$ growth in control samples. Thus, chitosanases have a promising advantage as an antibiotic agent, since they combat against biofilms formed by pathogenic bacteria (Muslim et al., 2016). An antimicrobial agent (protein BL-DZ1 with a molecular weight of $14 \mathrm{kDa}$ ) isolated from a tropical marine strain of $B$. licheniformis acts as a potential antibiofilm agent (Dusane et al., 2013).

Thus, Bacillus spp. are characterized by the wide range of antibiotic substances they produce, which in turn determine their high antagonistic activity against various microorganisms. Therefore, the creation of drugs based on bacilli or their metabolites is an important and promising aspect for destroying the integrity of biofilm matrices. Coupled with the use in medicine, it is important to obtain environmentally friendly products; therefore, new technologies based on bacilli are no less important in agriculture.

\section{BACILLARY ENZYMES IN AGRICULTURE}

\section{As an Additive for Animal Feed}

To increase the efficiency of animal feed use, microbial enzymes that increase the digestibility of nutrients are used (Choct, 2006). Commercially available feed enzymes include phytases, proteases, $\alpha$-galactosidases, xylanases, and $\alpha$-amylases, which are mainly used to supplement the feed of pigs and poultry (Selle and Ravindran, 2007). The logical candidates for generating feed enzyme products are non-pathogenic and non-toxigenic microbial strains (Pariza and Cook, 2010).

Microbial amylases and proteases are introduced into enzyme-based multi-enzyme complexes that enhance digestive function by complementing the action of similar endogenous gastrointestinal enzymes in birds. The sources of these enzymes are usually B. amyloliquefaciens, B. licheniformis, and B. subtilis (Contesini et al., 2018). B. subtilis is a cosmopolitan probiotic bacterium with an excellent enzymatic profile that can improve nutrient absorption and stimulate healthy growth. It has been described that Bacillus enzymes can help marine animals absorb nutrients from non-traditional and economical plant resources (Olmos Soto, 2017). It was also reported that using fermented soybean meal (SM) of Bacillus pumillus SE5 (BP; BPFSM) as a feed has a beneficial effect on antioxidant capacity, innate immunity, and intestinal health in young Japanese Sebastes (Rahimnejad et al., 2019).

Industrial poultry is the largest consumer of feed enzymes, which have been established as a tool that improves the efficiency of nutrient assimilation and energy (Romero et al., 2013).

Compounds such as phytates cause significant decrease in the nutritional value of animal feed. Phytases of bacteria of the genus Bacillus are promising as feed additives. These enzymes are characterized by elevated stability both thermally and in a wide range of $\mathrm{pH}$ (from 3.0 to 9.0); resistance to the action of proteolytic enzymes of the gastrointestinal tract; and high affinity for calcium ions, which are involved in the stabilization of the enzyme molecule and the formation of its active center (Balaban et al., 2016). This integration of properties makes bacillary phytases suitable for functioning in the digestive tract of birds (Lei et al., 2013). A $\beta$-propeller phytase of Bacillus ginsengihumi was previously isolated and characterized (Akhmetova et al., 2013). This B. ginsengihumi phytase was observed to thrive well in the acidic conditions similar to that the crop and small intestine in poultry (Dersjant-Li et al., 2015), as well as to have a thermal stability that corresponds to the conditions for the production of granular feed $\left(65-80^{\circ} \mathrm{C}\right.$; Lei et al., 2013). The results of another study showed that adding subtilisin-like $B$. pumilus proteinase to the diet of broiler chickens has a positive effect on growth performance, nutrient digestibility, and meat quality (Koryagina et al., 2019).

An alternative to the outright delivery of these enzymes into the animal is also possible; bacteria that can synthesize extracellular enzymes directly in the digestive tract of the host organism are used as a feed additive. The nutritional effect of $B$. subtilis spores on growth rates, blood metabolites, antioxidant levels, and digestive enzyme activity in growing quail was studied (Latorre et al., 2016; Abdel-Moneim et al., 2019). It was found that the B. subtilis strain CM40 possesses the desired in vitro probiotic properties and may be a potential candidate for supplementation in animal feed (Mingmongkolchai and Panbangred, 2017). Three probiotic strains of Bacillus (B. subtilis natto, B. licheniformis, and B. cereus) showed favorable effects on chickens with minimal strain specificity (Gong et al., 2018). With recent bans on the growth-promoting use of antibiotics, alternative strategies are needed to improve the performance of agricultural animals (Brüssow, 2017). The reduced use of antibiotics in poultry has significantly increased the occurrence of subclinical necrotic enteritis (SNE) caused by Clostridium perfringens (CP), which compels researchers to seek alternatives to antibiotic growth stimulants (AGPs), in particular probiotics. It has been shown that the nutritional supplement based on B. licheniformis H2 can effectively prevent the occurrence of CPE-induced SNE and improve the growth rates of broiler chickens suffering from SNE, by improving intestinal development, antioxidant ability, and apoptosis (Zhao et al., 2019). It is also known that the genus Bacillus is widely used as probiotics in feed additives for pigs (B. amyloliquefaciens 15078, Bacillus mojavensis 10894, and $B$. subtilis 15130) and in aquaculture (B. licheniformis Dahb1, B. pumilus, and Bacillus coagulans B16; Jers et al., 2017; Kuebutornye et al., 2019). To obtain optimal effects, the correct choice of probiotic strains, as well as various combinations of enzymes, which are important for improving nutrition and protecting the health of domestic animals, is necessary. Further research in this direction is needed to expand the arsenal of drugs based on bacteria and their enzymes.

\section{Degradation of Feathers, Wool, and Hair by Bacillary Enzymes}

Feathers of fowls have become one of the main pollutants due to their recalcitrant nature. A feather consisting of $90 \%$ keratin can be a good source of peptides, amino acids, and minerals for use as an organic fertilizer. The use of keratinolytic bacteria can become a sustainable and alternative tool for 
promoting and improving organic farming, agroecosystems, human health, soil biological activity, and the environment as a whole. Bacterial keratinases are serine-type proteases that exhibit optimal activity at a $\mathrm{pH}$ of $6-9$ and a temperature range of $30-50^{\circ} \mathrm{C}$ (Tamreihao et al., 2019).

Effective feather decomposing bacteria were obtained and identified as B. pumilus GRK (Ramakrishna et al., 2017), B. licheniformis ALW1 (Abdel-Fattah et al., 2018), and B. amyloliquefaciens S13 (Hamiche et al., 2019). Proteases are of particular interest because of their effect on insoluble keratin substrates of various origins. Proteases are widely used in the leather industry to remove hair from animal skins. Excellent hair removal efficiency with proteinases from bacteria such as B. mojavensis SA has been reported (Hammami et al., 2018). Similar properties have likewise been established in Bacillus aerius NSMk2 (Bhari et al., 2019), Bacillus thuringiensis (Agasthya et al., 2013), B. pumilus SCU11 (Wang et al., 2016), Bacillus sp., SB12 (Briki et al., 2016), and B. subtilis KT004404 (Rehman et al., 2017).

\section{SUMMARY}

Microorganisms produce various types of extracellular enzymes for metabolic support, self-defense, and maintenance of normal physiological state. Microbial biotechnology, paralleled with the achievements of genetic and protein engineering, offer great opportunities for creating targeted enzyme-based biologically active substances. Proteolytic enzymes constitute one of the most diverse groups of microbial proteins in terms of properties. Thanks to the varied specificity and multiplicity of properties,

\section{REFERENCES}

Abdel-Fattah, A. M., El-Gamal, M. S., Ismail, S. A., Emran, M. A., and Hashem, A. M. (2018). Biodegradation of feather waste by keratinase produced from newly isolated Bacillus licheniformis ALW1. J. Genet. Eng. Biotechnol. 16, 311-318. doi: 10.1016/j.jgeb.2018.05.005

Abdel-Moneim, A. E., Selim, D. A., Basuony, H. A., Sabic, E. M., Saleh, A. A., and Ebeid, T. A. (2019). Effect of dietary supplementation of Bacillus subtilis spores on growth performance, oxidative status, and digestive enzyme activities in Japanese quail birds. Trop. Anim. Health Prod. 52, 671-680. doi: 10.1007/ s11250-019-02055-1

Agasthya, A. S., Sharma, N., Mohan, A., and Mahal, P. (2013). Isolation and molecular characterisation of alkaline protease producing Bacillus thuringiensis. Cell Biochem. Biophys. 66, 45-51. doi: 10.1007/s12013-012-9396-4

Agrebi, R., Haddar, A., Hajji, M., Frikha, F., Manni, L., Jellouli, K., et al. (2009). Fibrinolytic enzymes from a newly isolated marine bacterium Bacillus subtilis A26: characterization and statistical media optimization. Can. J. Microbiol. 55, 1049-1061. doi: 10.1139/W09-057

Agrebi, R., Hmidet, N., Hajji, M., Ktari, N., Haddar, A., Fakhfakh-Zouari, N., et al. (2010). Fibrinolytic serine protease isolation from Bacillus amyloliquefaciens An6 grown on Mirabilis jalapa tuber powders. Appl. Biochem. Biotechnol. 162, 75-88. doi: 10.1007/s12010-009-8800-Z

Akhmetova, A. I., Nyamsuren, C., Balaban, N. P., and Sharipova, M. R. (2013). Isolation and characterization of a new bacillary phytase. Bioorg. Chem. 39, 384-389. doi: 10.1134/S1068162013040031

Anandharaj, M., Sivasankari, B., Siddharthan, N., Rani, R. P., and Sivakumar, S. (2016). Production, purification, and biochemical characterization of thermostable metallo-protease from novel Bacillus alkalitelluris TWI3 isolated from tannery waste. Appl. Biochem. Biotechnol. 178, 1666-1686. doi: 10.1007/ s12010-015-1974-7 these enzymes are widely used in biotechnology and medicine. The genus Bacillus is probably the most important bacterial source of proteases and is capable of producing high yields of neutral and alkaline proteolytic enzymes with remarkable properties, such as high resistance to extreme temperatures, $\mathrm{pH}$, organic solvents, and oxidizing agents. At present, advancement in the use of new genomics and proteomics data to create new pharmaceutical drugs is widely observed. Much headway has been made in the development and implementation of technologies for the production of novel and safe feed additives that improve the health and productivity of agricultural animals, reduce the economic cost of feed, and improve the environment. Another important economic and environmental challenge is the use of feather as a raw material for the creation of effective feed and fertilizer additives. Several studies are aimed at solving these important practical problems.

\section{AUTHOR CONTRIBUTIONS}

All authors listed have made a substantial, direct, and intellectual contribution to the work and approved it for publication.

\section{FUNDING}

This work was performed in accordance with the Russian Government Program of Competitive Growth of Kazan Federal University and supported by the Russian Science Foundation (project no. 16-16-04062).

Balaban, N. P., Suleimanova, A. D., Valeeva, L. R., Shakirov, E. V., and Sharipova, M. R. (2016). Structural characteristics and catalytic mechanism of Bacillus $\beta$-propeller phytases. Biochemistry 81, 785-793. doi: 10.1134/ S0006297916080010

Baneyx, F. (1999). Recombinant protein expression in Escherichia coli. Curr. Opin. Biotechnol. 10, 411-421. doi: 10.1016/S0958-1669(99)00003-8

Bhari, R., Kaur, M., and Singh, R. S. (2019). Thermostable and halotolerant keratinase from Bacillus aerius NSMk2 with remarkable dehairing and laundary applications. J. Basic Microbiol. 59, 555-568. doi: 10.1002/jobm.201900001

Briki, S., Hamdi, O., and Landoulsi, A. (2016). Enzymatic dehairing of goat skins using alkaline protease from Bacillus sp. SB12. Protein Expr. Purif. 121, 9-16. doi: 10.1016/j.pep.2015.12.021

Brüssow, H. (2017). Adjuncts and alternatives in the time of antibiotic resistance and in-feed antibiotic bans. Microb. Biotechnol. 10, 674-677. doi: 10.1111/ 1751-7915.12730

Choct, M. (2006). Enzymes for the feed industry: past, present and future. World Poult. 62, 5-15. doi: 10.1079/WPS200480

Contesini, F. J., Melo, R. R., and Sato, H. H. (2018). An overview of Bacillus proteases: from production to application. Crit. Rev. Biotechnol. 38, 321-334. doi: 10.1080/07388551.2017.1354354

Costerton, J. W., Lewandowski, Z., Caldwell, D. E., Korber, D. R., and Lappin-Scott, H. M. (1995). Microbial biofilms. Annu. Rev. Microbiol. 49, 711-745. doi: 10.1146/annurev.mi.49.100195.003431

Cui, W., Han, L., Suo, F., Liu, Z., Zhou, L., and Zhou, Z. (2018). Exploitation of Bacillus subtilis as a robust workhorse for production of heterologous proteins and beyond. World J. Microbiol. Biotechnol. 34:145. doi: 10.1007/s11274-018-2531-7

Danilova, Y. V., Cheremin, A. M., Zamaleeva, A. I., Mardanova, A. M., Zamalyutdinova, N. M., and Sharipova, M. R. (2012). Thrombolytic and fibrinolytic activity of bacterial proteases. Cell. Transplant. Tissue Eng. $8,1-3$. 
Danilova, Y. V., Shagimardanova, E. I., Margulis, A. B., Toymentseva, A. A., Balabana, N. P., Rudakova, N. L., et al. (2014). Bacterial enzymes effectively digest Alzheimer's beta-amyloid peptide. Brain Res. Bull. 108, 113-117. doi: 10.1016/j.brainresbull.2014.08.009

Dersjant-Li, Y., Awati, A., Schulze, H., and Partridge, G. (2015). Phytase in non-ruminant animal nutri-tion: a critical review on phytase activities in the gastrointestinal tract and influencing factors. J. Sci. Food Agric. 95, 878-896. doi: 10.1002/jsfa.6998

Dos Santos Aguilar, J. G., and Sato, H. H. (2018). Microbial proteases: production and application in obtaining protein hydrolysates. Food Res. Int. 103, 253-262. doi: 10.1016/j.foodres.2017.10.044

Dusane, D. H., Damare, S. R., Nancharaiah, Y. V., Ramaiah, N., Venugopalan, V. P., Kumar, A. R., et al. (2013). Disruption of microbial biofilms by an extracellular protein isolated from epibiotic tropical marine strain of Bacillus licheniformis. PLoS One 8:e64501. doi: 10.1371/journal.pone.0064501

Elchinger, P. H., Delattre, C., Faure, S., Roy, O., Badel, S., and Bernardi, T. (2015). Immobilization of proteases on chitosan for the development of films with anti-biofilm properties. Int. J. Biol. Macromol. 72, 1063-1068. doi: 10.1016/j.ijbiomac.2014.09.061

Elchinger, P. H., Delattre, C., Faure, S., Roy, O., Badel, S., Bernardi, T., et al. (2014). Effect of proteases against biofilms of Staphylococcus aureus and Staphylococcus epidermidis. Lett. Appl. Microbiol. 59, 507-513. doi: 10.1111/lam.12305

Flemming, H. -C., Wingender, J., Szewzyk, U., Steinberg, P., Rice, S. A., and Kjelleberg, S. (2016). Biofilms: an emergent form of bacterial life. Nat. Rev. Microbiol. 14, 563-575. doi: 10.1038/nrmicro.2016.94

Galie, S., Garcia-Gutierrez, C., Miguelez, E. M., Villar, C. J., and Lombo, F. (2018). Biofilms in the food industry: health aspects and control methods. Front. Microbiol. 9:898. doi: 10.3389/fmicb.2018.00898

Garcia-Fruitos, E. (2012). Lactic acid bacteria: a promising alternative for recombinant protein production. Microb. Cell Fact. 11:157. doi: 10.1186/ 1475-2859-11-157

Ghasemi, Y., Dabbagh, F., and Ghasemian, A. (2012). Cloning of a fibrinolytic enzyme (subtilisin) gene from Bacillus subtilis in Escherichia coli. Mol. Biotechnol. 52, 1-7. doi: 10.1007/s12033-011-9467-6

Gong, L., Wang, B., Mei, X., Xu, H., Qin, Y., Li, W., et al. (2018). Effects of three probiotic Bacillus on growth performance, digestive enzyme activities, antioxidative capacity, serum immunity, and biochemical parameters in broilers. Anim. Sci. J. 89, 1561-1571. doi: 10.1111/asj.13089

Gurumallesh, P., Alagu, K., Ramakrishnan, B., and Muthusamy, S. (2019). A systematic reconsideration on proteases. Int. J. Biol. Macromol. 128, 254-267. doi: 10.1016/j.ijbiomac.2019.01.081

Hamiche, S., Mechri, S., Khelouia, L., Annane, R., El Hattab, M., Badis, A., et al. (2019). Purification and biochemical characterization of two keratinases from Bacillus amyloliquefaciens S13 isolated from marine brown alga Zonaria tournefortii with potential keratin-biodegradation and hide-unhairing activities. Int. J. Biol. Macromol. 122, 758-769. doi: 10.1016/j.ijbiomac.2018.10.174

Hammami, A., Fakhfakh, N., Abdelhedi, O., Nasri, M., and Bayoudh, A. (2018). Proteolytic and amylolytic enzymes from a newly isolated Bacillus mojavensis SA: characterization and applications as laundry detergent additive and in leather processing. Int. J. Biol. Macromol. 108, 56-68. doi: 10.1016/j. ijbiomac.2017.11.148

Hardy, J., and Selkoe, D. J. (2002). The amyloid hypothesis of Alzheimer's disease: progress and problems on the road to therapeutics. Science 297, 353-356. doi: 10.1126/science.1072994

Harwood, C. R., and Cranenburgh, R. (2008). Bacillus protein secretion: an unfolding story. Trends Microbiol. 16, 73-79. doi: 10.1016/j.tim.2007.12.001

Hasan, F., Shah, A. A., and Hameed, A. (2006). Industrial applications of microbial lipases. Enzym. Microb. Technol. 39, 235-251. doi: 10.1016/j. enzmictec.2005.10.016

Hassanein, W. A., Kotb, E., Awny, N. M., and El-Zawahry, Y. A. (2011). Fibrinolysis and anticoagulant potential of a metallo protease produced by Bacillus subtilis K42. J. Biosci. 36, 773-779. doi: 10.1007/s12038-011-9151-9

Hsu, R. L., Lee, K. T., Wang, J. H., Lee, L. Y., and Chen, R. P. (2009). Amyloiddegrading ability of nattokinase from Bacillus subtilis natto. Agric. Food Chem. 57, 503-508. doi: 10.1021/jf803072r

Jers, C., Strube, M. L., Cantor, M. D., Nielsen, B. K. K., Sorensen, O. B., Boye, M., et al. (2017). Selection of Bacillus species for targeted in situ release of prebiotic galacto-rhamnogalacturonan from potato pulp in piglets. Appl. Microbiol. Biotechnol. 101, 3605-3615. doi: 10.1007/s00253-017-8176-x
Jespers, L., Vanwetswinkel, S., Lijnen, H. R., van Herzeele, N., van Hoef, B., and Demarsin, E. (1999). Structural and functional basis of plasminogen activation by staphylokinase. Thromb. Haemost. 81, 479-485. doi: 10.1055/ s-0037-1614509

Jujjavarapu, S. E., and Dhagat, S. (2019). Evolutionary trends in industrial production of $\alpha$-amylase. Recent Pat. Biotechnol. 13, 4-18. doi: 10.217 4/2211550107666180816093436

Kamal, S., Rehman, S., and Iqbal, H. M. (2016). Biotechnological valorization of proteases: from hyperproduction to industrial exploitation-a review. Environ. Prog. Sustain. Energy 36, 511-522. doi: 10.1002/ep.12447

Khmelevskaia, I. G. (2000). Immunocorrective effect of proteolytic enzymes on antibody genesis in mice subjected to infectious burn trauma and treatment with antibiotics. Zh. Mikrobiol. Epidemiol. Immunobiol. 6, 48-51.

Kim, S. B., Lee, D. W., Cheigh, C. I., Choe, E. A., Lee, S. J., Hong, Y. H., et al. (2006). Purification and characterization of a fibrinolytic subtilisin-like protease of Bacillus subtilis TP-6 from an Indonesian fermented soybean. J. Ind. Microbiol. Biotechnol. 33, 436-444. doi: 10.1007/s10295-006-0085-4

Ko, J. H., Yan, J. P., Zhu, L., and Qi, Y. P. (2004). Identification of two novel fibrinolytic enzymes from Bacillus subtilis QK02. Comp. Biochem. Physiol. C Toxicol. Pharmaco. 137, 65-74. doi: 10.1016/j.cca.2003.11.008

Koga, Y., Tanaka, S., Sakudo, A., Tobiume, M., Aranishi, M., Hirata, A., et al. (2014). Proteolysis of abnormal prion protein with a thermostable protease from Thermococcus kodakarensis KOD1. Appl. Microbiol. Biotechnol. 98, 2113-2120. doi: 10.1007/s00253-013-5091-7

Koryagina, A. O., Troshagina, D. S., Suleymanova, A. D., Rudakova, N. L., Mardanova, A. M., Smolentsev, S. Y., et al. (2019). Bacterial enzymes as potential feed additives in poultry farming. Uchenye Zapiski Kazanskogo Universiteta. Seriya Estestvennye Nauki 161, 459-471. doi: 10.26907/2542-064X.2019.3.459-471

Kuebutornye, F. K. A., Abarike, E. D., and Lu, Y. (2019). A review on the application of Bacillus as probiotics in aquaculture. Fish Shellfish Immunol. 87, 820-828. doi: 10.1016/j.fsi.2019.02.010

Latorre, J. D., Hernandez-Velasco, X., Wolfenden, R. E., Vicente, J. L., Wolfenden, A. D., Menconi, A., et al. (2016). Evaluation and selection of Bacillus species based on enzyme production, antimicrobial activity, and biofilm synthesis as direct-fed microbial candidates for poultry. Front. Vet. Sci. 3:95. doi: 10.3389/fvets.2016.00095

Lei, X. G., Weaver, J. D., Mullaney, E., Ullah, A. H., and Azain, M. J. (2013). Phytase, a new life for an "old" enzyme. Annu. Rev. Anim. Biosci. 1, 283-309. doi: 10.1146/annurev-animal-031412-103717

Ma, S. K., Gruber, J., Davis, C., Newman, L., Gray, D., Wang, A., et al. (2010). A green-by-design biocatalytic process for atorvastatin intermediate. Green Chem. 12, 81-86. doi: 10.1039/B919115C

Mahajan, P. M., Nayak, S., and Lele, S. S. (2012). Fibrinolytic enzyme from newly isolated marine bacterium Bacillus subtilis ICTF-1: media optimization, purification and characterization. J. Biosci. Bioeng. 113, 307-314. doi: 10.1016/j. jbiosc.2011.10.023

Marcato-Romain, C. E., Pechaud, Y., Paul, E., Girbal-Neuhauser, E., and Dossat-Létisse, V. (2012). Removal of microbial multi-species biofilms from the paper industry by enzymatic treatments. Biofouling 28, 305-314. doi: 10.1080/08927014.2012.673122

Mhamdi, S., Ktari, N., Hajji, S., Nasri, M., and Sellami Kamoun, A. (2017). Alkaline proteases from a newly isolated Micromonospora chaiyaphumensis S103: characterization and application as a detergent additive and for chitin extraction from shrimp shell waste. Int. J. Biol. Macromol. 94, 415-422. doi: 10.1016/j.ijbiomac.2016.10.036

Mienda, B. S., Yahya, A., Galadima, I. A., and Shamsir, M. S. (2014). An overview of microbial proteases for industrial applications. Res. J. Pharm. Biol. Chem. Sci. 5, 388-396.

Mingmongkolchai, S., and Panbangred, W. (2017). In vitro evaluation of candidate Bacillus spp. for animal feed. J. Gen. Appl. Microbiol. 63, 147-156. doi: 10.2323/jgam.2016.09.002

Mitrofanova, O., Mardanova, A., Evtugyn, V., Bogomolnaya, L., and Sharipova, M. (2017). Effects of Bacillus serine proteases on the bacterial biofilms. Biomed. Res. Int. 2017:8525912. doi: 10.1155/2017/8525912

Mukherjee, A. K., Chattopadhyay, P., Kar, S. K., Rai, S. K., and Thakur, R. (2012). Bafibrinase: a non-toxic, non-hemorrhagic, direct-acting fibrinolytic serine protease from Bacillus sp. strain AS-S20-I exhibits in vivo anticoagulant activity and thrombolytic potency. Biochimie 94, 1300-1308. doi: 10.1016/j. biochi.2012.02.027 
Muslim, S. N., Al-Kadmy, I. M. S., Hussein, N. H., Mohammed Ali, A. N., Taha, B. M., Aziz, S. N., et al. (2016). Chitosanase purified from bacterial isolate Bacillus licheniformis of ruined vegetables displays broad spectrum biofilm inhibition. Microb. Pathog. 100, 257-262. doi: 10.1016/j.micpath.2016.10.001

Narasimhan, M. K., Ethiraj, S., Krishnamurthi, T., and Rajesh, M. (2018). Purification, biochemical, and thermal properties of fibrinolytic enzyme secreted by Bacillus cereus SRM-001. Prep. Biochem. Biotechnol. 48, 34-42. doi: 10.1080/10826068.2017.1387560

Nounou, M. I., Zaghloul, T. I., Ahmed, N. A., Eid, A. A., and El-Khordagui, L. K. (2017). Skin permeability enhancement by Bacillus subtilis alkaline protease: application to transdermal drug delivery. Int. J. Pharm. 529, 423-432. doi: 10.1016/j.ijpharm.2017.06.057

Olmos Soto, J. (2017). Bacillus probiotic enzymes: external auxiliary apparatus to avoid digestive deficiencies, water pollution, diseases, and economic problems in marine cultivated animals. Adv. Food Nutr. Res. 80, 15-35. doi: 10.1016/bs.afnr.2016.11.001

Pariza, M. W., and Cook, M. (2010). Determining the safety of enzymes used in animal feed. Regul. Toxicol. Pharmacol. 56, 332-342. doi: 10.1016/j. yrtph.2009.10.005

Peng, Y., Yang, X. J., Xiao, L., and Zhang, Y. Z. (2004). Cloning and expression of a fibrinolytic enzyme (subtilisin DFE) gene from Bacillus amyloliquefaciens DC-4 in Bacillus subtilis. Res. Microbiol. 155, 167-173. doi: 10.1016/j. resmic.2003.10.004

Plotnikov, M. B., Dygai, A. M., Aliev, O. I., Chernyshova, G. A., Smol'yakova, V. I., Vasilev, A. S., et al. (2009). Antithrombotic and thrombolytic effects of a new proteolytic preparation Trombovazim. Bull. Exp. Biol. Med. 147, 438-440. doi: 10.1007/s10517-009-0521-3

Rahimnejad, S., Lu, K., Wang, L., Song, K., Mai, K., Davis, D. A., et al. (2019). Replacement of fish meal with Bacillus pumillus SE5 and Pseudozyma aphidis ZR1 fermented soybean meal in diets for Japanese seabass (Lateolabrax japonicus). Fish Shellfish Immunol. 84, 987-997. doi: 10.1016/j.fsi.2018.11.009

Ramakrishna, R. M., Sathi, R. K., Ranjita, C. Y., Bee, H., and Reddy, G. (2017). Effective feather degradation and keratinase production by Bacillus pumilus GRK for its application as bio-detergent additive. Bioresour. Technol. 243, 254-263. doi: 10.1016/j.biortech.2017.06.067

Razzaq, A., Shamsi, S., Ali, A., Ali, Q., Sajjad, M., Malik, A., et al. (2019). Microbial proteases applications. Front. Bioeng. Biotechnol. 7:110. doi: 10.3389/ fbioe.2019.00110

Regmi, S., Choi, Y. H., Choi, Y. S., Kim, M. R., and Yoo, J. C. (2017). Antimicrobial peptide isolated from Bacillus amyloliquefaciens K14 revitalizes its use in combinatorial drug therapy. Folia Microbiol. 62, 127-138. doi: 10.1007/s12223-016-0479-2

Rehman, R., Ahmed, M., Siddique, A., Hasan, F., Hameed, A., and Jamal, A. (2017). Catalytic role of thermostable metalloproteases from Bacillus subtilis KT004404 as dehairing and destaining agent. Appl. Biochem. Biotechnol. 181, 434-450. doi: 10.1007/s12010-016-2222-5

Romero, L. F., Parsons, C. M., Utterback, P. L., Plumstead, P. W., and Ravindran, V. (2013). Comparative effects of dietary carbohydrases without or with protease on the ileal digestibility of energy and amino acids and AMEn in young broilers. Anim. Feed Sci. Technol. 181, 35-44. doi: 10.1016/j.anifeedsci.2013.02.001

Selle, P. H., and Ravindran, V. (2007). Microbial phytase in poultry nutrition. Anim. Feed Sci. Technol. 135, 1-41. doi: 10.1016/j.anifeedsci.2006.06.010

Shataeva, L. K., Orlievskaia, O. V., Chichkovskaia, G. V., and Samsonov, G. V. (1973). Enzymatic activity of terrilytin. Biokhimiia 38, 1169-1174.

Singh, S., and Bajaj, B. K. (2016). Bioprocess optimization for production of thermoalkali-stable protease from Bacillus subtilis K-1 under solid state fermentation. Prep. Biochem. Biotechnol. 46, 717-724. doi: 10.1080/ 10826068.2015.1135455

Singh, S., and Bajaj, B. K. (2017). Agroindustrial/forestry residues as substrates for production of thermoactive alkaline protease from Bacillus licheniformis K-3 having multifaceted hydrolytic potential. Waste Biomass Valoriz. 8, 453-462. doi: 10.1007/s12649-016-9577-2

Souza, P. M., and Magalhaes, P. O. (2010). Application of microbial $\alpha$-amylase in industry-a review. Braz. J. Microbiol. 41, 850-861. doi: 10.1590/ S1517-83822010000400004

Suleimanova, A. D., Chastukhina, I. B., Valeeva, L. R., Itkina, D. L., and Sharipova, M. R. (2016). Cloning and heterologous expression of phytase gene from Pantoea sp. 3.5.1. Bionanoscience 6, 338-340. doi: 10.1007/ s12668-016-0227-8

Tamreihao, K., Mukherjee, S., Khunjamayum, R., Devi, L. J., Asem, R. S., and Ningthoujam, D. S. (2019). Feather degradation by keratinolytic bacteria and biofertilizing potential for sustainable agricultural production. J. Basic Microbiol. 59, 4-13. doi: 10.1002/jobm.201800434

Thallinger, B., Prasetyo, E. N., Nyanhongo, G. S., and Guebitz, G. M. (2013). Antimicrobial enzymes: an emerging strategy to fight microbes and microbial biofilms. Biotechnol. J. 8, 97-109. doi: 10.1002/biot.201200313

Thu, N. T. A., Khue, N. T. M., Huy, N. D., Tien, N. Q. D., and Loc, N. H. (2019). Characterizations and fibrinolytic activity of serine protease from Bacillus subtilis C10. Curr. Pharm. Biotechnol. 21, 110-116. doi: 10.217 4/1389201020666191002145415

Troshagina, D. S., Suleimanova, A. D., Itkina, D. L., and Sharipova, M. R. (2018). Cloning of phytase genes from Pantoea sp. 3.5 .1 and Bacillus ginsengihumi M2.11 in Pichia pastoris. Bionanoscience 8, 1045-1053. doi: 10.1007/s12668-018-0563-y

Vijayaraghavan, P., and Vincent, S. G. (2014). Statistical optimization of fibrinolytic enzyme production using agroresidues by Bacillus cereus IND1 and its thrombolytic activity in vitro. Biomed. Res. Int. 2014:725064. doi: 10.1155/ 2014/725064

Volpato, G., Rodrigues, R. C., and Fernandez-Lafuente, R. (2010). Use of enzymes in the production of semi-synthetic penicillins and cephalosporins: drawbacks and perspectives. Curr. Med. Chem. 17, 3855-3873. doi: 10.2174/ 092986710793205435

Wang, C. T., Ji, B. P., Li, B., Nout, R., Li, P. L., Ji, H., et al. (2006). Purification and characterization of a fibrinolytic enzyme of Bacillus subtilis DC33, isolated from Chinese traditional Douchi. J. Ind. Microbiol. Biotechnol. 33, 750-758. doi: 10.1007/s10295-006-0111-6

Wang, C., Yu, S., Song, T., He, T., Shao, H., and Wang, H. (2016). Extracellular proteome profiling of Bacillus pumilus SCU11 producing alkaline protease for dehairing. J. Microbiol. Biotechnol. 26, 1993-2005. doi: 10.4014/ jmb.1602.02042

Wang, S. H., Zhang, C., Yang, Y. L., Diao, M., and Bai, M. F. (2008). Screening of a high fubrinolytic enzyme producing strain and characterization of the fibrinolytic enzyme produced from Bacillus subtilis LD-8547. J. Microbiol. Biotechnol. 24, 475-482. doi: 10.1007/s11274-007-9496-2

Yang, H. Q., Liu, L., Li, J. H., Du, G. C., and Chen, J. (2011). Heterologous expression, biochemical characterization, and overproduction of alkaline $\alpha$-amylase from Bacillus alcalophilus in Bacillus subtilis. Microb. Cell Fact. 10:77. doi: 10.1186/1475-2859-10-77

Yao, Z., Kim, J. A., and Kim, J. H. (2019). Characterization of a fibrinolytic enzyme secreted by bacillus velezensis BS2 isolated from sea squirt jeotgal. J. Microbiol. Biotechnol. 29, 347-356. doi: 10.4014/jmb.1810.10053

Yoshioka, M., Miwa, T., Horii, H., Takata, M., Yokoyama, T., Nishizawa, K., et al. (2007). Characterization of a proteolytic enzyme derived from a Bacillus strain that effectively degrades prion protein. Appl. Microbiol. 102, 509-515. doi: $10.1111 /$ j.1365-2672.2006.03080.x

Zhao, H. Y., and Feng, H. (2018). Engineering Bacillus pumilus alkaline serine protease to increase its low-temperature proteolytic activity by directed evolution. BMC Biotechnol. 18:34. doi: 10.1186/s12896-018-0451-0

Zhao, Y., Zeng, D., Wang, H., Qing, X., Sun, N., Xin, J., et al. (2019). Dietary probiotic Bacillus licheniformis $\mathrm{H}_{2}$ enhanced growth performance, morphology of small intestine and liver, and antioxidant capacity of broiler chickens against Clostridium perfringens-induced subclinical necrotic enteritis. Probiotics Antimicrob. Proteins. doi: 10.1007/s12602-019-09597-8 [Epub ahead of print]

Conflict of Interest: The authors declare that the research was conducted in the absence of any commercial or financial relationships that could be construed as a potential conflict of interest.

Copyright (c) 2020 Danilova and Sharipova. This is an open-access article distributed under the terms of the Creative Commons Attribution License (CC BY). The use, distribution or reproduction in other forums is permitted, provided the original author(s) and the copyright owner(s) are credited and that the original publication in this journal is cited, in accordance with accepted academic practice. No use, distribution or reproduction is permitted which does not comply with these terms. 